\title{
OS VELHOS E OS NOVOS DIREITOS DOS IDOSOS
}

\author{
Ana Lúcia Alves Feliciani ${ }^{1}$
}

INTRODUÇÃO

Ensina Pontes de Miranda que "o primeiro direito de personalidade é o de adquirir direitos, pretensões, ações e exceções e de assumir deveres, obrigações, ou situações passivas em ação ou exceção".

Mais de 60 anos após a Declaração Universal dos Direitos do Homem³ acentuam-se os questionamentos acerca dos seus velhos e novos direitos, dos que já foram declarados, positivados, adquiridos, dos que já guardam essas condições, mas não ainda efetivados, bem como de outros quiçá antes nem pensados, porque não verificada a necessidade de sua proteção. Como ensina Bobbio ${ }^{4}$, "os direitos não nascem todos de

1 Doutoranda em Direito pela Universidade Federal do Rio Grande do Sul (UFRGS); Bacharel em Direito pela Pontifícia Universidade Católica do Rio Grande do Sul PUCRS; Especialista em Direito Civil Aplicado pela UFRGS; Mestre em Direito pela UFRGS; Professora nas Faculdades Integradas São Judas Tadeu em Porto Alegre; Assessora Jurídica da Procuradoria-Geral do Estado do Rio Grande do Sul; Advogada.

2 PONTES DE MIRANDA. Tratado de Direito Privado. Rio de Janeiro: Borsoi. 1956. Tomo VII, parágrafo 731, p. 11.

3 BOBBIO, Norberto. A era dos direitos. Tradução de Carlos Nelson Coutinho; apresentação de Celso Lafer - Nova Ed. Rio de Janeiro: Elsevier, 2004, p. 26. Anota o autor que "a Declaração Universal dos Direitos do Homem representa a manifestação da única prova através da qual um sistema de valores pode ser considerado humanamente fundado e, portanto, reconhecido; e essa prova é o consenso geral acerca da sua validade".

4 BOBBIO, Norberto. Op. cit., p. 6. 
uma vez. Nascem quando devem ou podem nascer."

É certo pensar, contudo, que o direito à vida deve abarcar todas as formas de asseguramento desta, alcançando o ser desde que assim possa ser entendido, passando pelo nascimento com vida ${ }^{5}$, pela infância, pela juventude, pela fase adulta até o envelhecer, de sorte que a tutela da personalidade

não pode se conter em setores estanques, de um lado direitos humanos e de outro as chamadas situações jurídicas de direito privado. A pessoa, à luz do sistema constitucional, requer proteção integrada, que supere a dicotomia direito público e direito privado e atenda à cláusula geral fixada pelo texto maior, de promoção da dignidade da pessoa humana. ${ }^{6}$

Isso porque, para cada uma das fases da vida humana, há necessida- des que podem ser ditas especiais, reclamando garantias singulares, que consoam com as peculiaridades de cada condição, fazendo-as múltiplas em conformidade com as diferenças de cada uma desses "grupos"7, e que o Código Civil em vigor seguramente não mais pode atender, ainda que tenha sido recentemente "atualizado".

Essa ideia é muito bem desenvolvida por Orlando Gomes ${ }^{9}$ :

O Código Civil foi o estatuto orgânico da vida privada, elaborado para dar solução a todos os problemas da vida de relação dos particulares. Não é mais, a olhos vistos. Perdeu, com efeito, a generalidade e a completude. Suponho que jamais conseguirá recuperá-las.

$\mathrm{O}$ cidadão indiferenciado, que o Código tomava por modelo, é hoje o indivíduo qualificado e concreto que a si mesmo procura proteger-se pela inserção em categorias ou grupos, com estatuto próprio.

5 Resguardados os direitos do nascituro desde a concepção (art. 2º Código Civil de 2002).

6 TEPEDINO, Gustavo. Temas de Direito Civil. Rio de Janeiro: Renovar, 2004, p. 53.

7 Nesse sentido, Bobbio anota que "essa especificação ocorreu com relação seja ao gênero, seja às várias fases da vida, seja à diferença entre estado normal e estados excepcionais na existência humana. Com relação ao gênero, foram cada vez mais reconhecidas as diferenças específicas entre a mulher e o homem. Com relação às várias fases da vida, foram-se progressivamente diferenciando os direitos da infância e da velhice, por um lado, e os do homem adulto, por outro. Com relação aos estados normais e excepcionais, fez-se valer a exigência de reconhecer direitos especiais aos doentes, aos deficientes, aos doentes mentais, etc." Ob. cit., p. 59.

8 Lei n. 10.406 de 10 de janeiro de 2002.

9 GOMES, Orlando. A caminho dos microssistemas. In: . Novos temas de direito civil. Rio de Janeiro: Forense, 1983, p. 40-50. 
Ainda de acordo com Orlando Gomes, “o esvaziamento do Código Civil como estatuto da vida privada decorre ainda da migração para o plano constitucional de princípios gerais atinentes a instituições privadas, tais como a propriedade, a família e a autonomia privada”. ${ }^{10}$ Ele enseja que atualmente se compreenda que o Código Civil funciona como um direito residual. ${ }^{11}$

A esse processo, Natalino Irti $^{12}$ denominou de "decodificazione" ao referir que o "codici di settore appartengono alla medesima logica. I codici di settore non segnano um ritorno al codice, assia alla forma storica del codice, mas svoluppo e compimento del processo di decodificazione", já que "la figura integrale del civis cede all'individuo frazionario" ${ }^{13}$, em que "Il codice civile sopravvive soltanto como disciplina residuale". ${ }^{14}$

No entanto, posteriormente, em artigo intitulado “I cinquant'anni del codice civile»15, Irti não mais considerou a nossa era como a da descodificação. Ao contrário, reconhece a possibilidade de recodificação, por compreender os processos de codificação e descodificação como verdadeiras categorias históricas, e não lógicas, justificadas por contextos sociais, econômicos e políticos distintos, e, por essa razão, mutáveis. ${ }^{16}$

Essa individualização e a necessária proteção específica dos direitos correspondentes adaptada à dinâmica dos novos tempos deram ensejo a uma maré de leis especiais, que constituem verdadeiros universos legislativos $^{17}$, como é o caso da proteção dos direitos das crianças e dos adolescentes, do jovem, dos idosos, da mulher gestante aos alimentos e do consumidor, entre outros.

Os microssistemas e as leis especiais em comento, assim, atendendo a mandamentos universais e consti-

10 Ibid.

11 Ibid.

12 IRTI, Natalino. Codici di settore: Compimento della 'decodificazione'. Dirito e Societá, n. 2, p. 131-136, 2005.

13 Ibid.

14 Ibid.

15 IRTI, Natalino. I cinquant’anni del codice civile. Rivista di Diritto Civile, n. 3, 1992. p. 227 et seq.

16 Ibid., p. 227 et seq.

17 GOMES, Orlando. A caminho dos microssistemas. In: direito civil. Rio de Janeiro: Forense, 1983, p. 40-50. Novos temas de 
tucionais, buscam a proteção do direito à vida e da dignidade da pessoa humana, bem como a tutela geral dos direitos de personalidade ${ }^{18}$ a serem assegurados por meio da proteção da própria família.

Nesse plano, a proteção dos idosos tem merecido especial atenção dos juristas e da sociedade, ante verificação do aumento vertiginoso do número de longevos na população mundial. O envelhecimento da população mundial atinge percentuais significativos registrados pela $\mathrm{ONU}^{19}$, resultantes da queda das taxas de natalidade concomitantemente ao avanço da medicina, tecnologia e melhora da qualidade de vida.

O presente estudo busca apontar as necessárias condições para um envelhecer com dignidade, fazendo breves considerações acerca do direito à convivência familiar entre avós e netos, bem como do direito/dever alimentar que envolve os idosos. Para tanto, o estudo será dividido em quatro partes.
A primeira será dedicada unicamente ao exame das condições do envelhecer com dignidade; a segunda enfatizará o direito à convivência familiar entre os netos e os seus progenitores; a terceira analisará o direito e o dever alimentar dos idosos; e, por fim, na última parte, a análise estará voltada para os alimentos gravídicos e a eventual obrigação avoenga nesse particular.

\section{AS CONDIÇÕES DO ENVELHECER}

Sabendo-se que "ou envelhecemos ou morremos" ${ }^{20}$ e que o envelhecimento é um processo gradativo e natural, inerente ao ser humano, o conceito de idoso pode ser analisado sob diversos planos, seja sob o ponto de vista biológico, psicológico ou cronológico, conjugando-se aspectos culturais, sociais e temporais. Norberto Bobbio ${ }^{21}$ aponta a existência de três tipos de velhice:

18 LARENZ, Karl. Derecho Civil. Parte General. Edersa, 1978, p. 161-162. Há de entender-se por derecho general de la personalidad "el derecho al respeto, a la no lesión de la persona en todas sus manifestaciones imediatas dignas de protección (tales como lo declarado oralmente o escrito por la misma) y en la esfera privada e íntima, sustraída a la curiosidad y a la inoportunidad de otros, sin que con ello se dé ya una delimitación terminante y segura”.

19 IDOSOS são 10\% da população mundial. Disponível em: <http://www.onu-brasil. org.br/view_news.php?id=4726>. Acesso em: 4 maio 2008.

20 SÉGUIN, Elida. O idoso: aqui e agora. Rio de Janeiro: Lúmen Júris, 2001, p. 5.

21 BOBBIO, Norberto. O tempo da memória: de senectude e outros escritos autobiográficos. Tradução Daniela Versiani. Rio de Janeiro: Campus, 1997, p. 18. 
a cronológica, a burocrática e a psicológica ou subjetiva. A primeira é meramente formal, variando no espaço e no tempo a determinação legal e social deste limiar [...]. Estipula-se um patamar e todos os que o alcançarem são considerados idosos, sendo irrelevante as respectivas características. A burocrática corresponde ao acesso ao benefício, como a aposentadoria por idade, passe livre nos transportes, isenções fiscais, etc. A subjetiva é a mais complexa, por não dispor de parâmetros, depende do sentir de cada um.

Seguindo tendência mundial, o Estatuto do Idoso ${ }^{22}$ acolheu expressamente o critério cronológico, para determinar que idosos são pessoas com idade igual ou superior a 60 (sessenta) anos, estabelecendo também as necessárias condições para um envelhecimento com dignidade.

Não há considerações às condições psicológicas ou biológicas, nem culturais para o Estatuto do Idoso, mas aquelas por vezes associadas ao aspecto socioeconômico são pontuadas para fins previdenciários ou assistenciais, evidenciando que a "velhice burocrática", referida por Bobbio, foi também adotada pelo ordenamento jurídico brasileiro. ${ }^{23} \mathrm{~A}$ "velhice burocrática” vista, a rigor, como meio de proteção aos idosos, pode significar verdadeiro entrave à vida dessas pessoas. É o caso da aposentadoria compulsória aos 70 anos de idade, determinada no inciso II do art. 40 da Constituição Federal24, bem como da imposição ao regime

22 Lei n. 10.741 de $1^{\circ}$ de outubro de 2003.

23 A Lei 8.213/1991 trata dos benefícios de aposentadoria por invalidez (art. 42), por idade (art. 48), do auxílio-doença (art. 59), entre outros, enquanto a Lei 8.742/1993, que dispõe sobre a assistência social, tem como um de seus objetivos a proteção à velhice (art. $\left.2^{\circ}, \mathrm{I}\right)$.

24 No entanto, os questionamentos acerca de possível inconstitucionalidade da aposentadoria compulsória aos 70 anos de idade, prevista no art. 40, §º II, da Constituição Federal, resultam afastados em razão do pronunciamento do Supremo Tribunal Federal, no julgamento da Ação Direta de Inconstitucionalidade n. 815, que teve como relator 0 Ministro Moreira Alves, o qual se posicionou no sentido de que as normas constitucionais emanadas pelo poder constituinte originário não podem ter sua constitucionalidade examinada; somente as emendas se submetem a tal controle: EMENTA: - Ação direta de inconstitucionalidade. Parágrafos $1^{\circ}$ e $2^{\circ}$ do artigo 45 da Constituição Federal. - A tese de que há hierarquia entre normas constitucionais originárias dando azo à declaração de inconstitucionalidade de umas em face de outras e incompossível com o sistema de Constituição rígida. - Na atual Carta Magna "compete ao Supremo Tribunal Federal, precipuamente, a guarda da Constituição" (artigo 102, “caput”), o que implica dizer que essa jurisdição lhe é atribuída para impedir que se desrespeite a Constituição como um todo, e não para, com relação a ela, exercer o papel de fiscal do Poder Constituin- 
da separação obrigatória de bens aos maiores de 70 anos que contraírem matrimônio. $^{25}$

Tais mecanismos de proteção à velhice, de outro lado, alinham-se à proteção da dignidade da pessoa humana, preconizada no inciso III do art. $1^{\circ}$ da Constituição Federal de 1988, como fundamento da República Federativa do Brasil. Para os idosos, veio positivada no art. $2^{\circ}$ do Estatuto em comento, para assegurar-lhes todos os direitos fundamentais inerentes à pessoa humana, com vista à preservação de sua saúde física $e$ mental e seu aproveitamento moral, intelectual, espiritual e social, em condições de liberdade e dignidade, garantindo-lhes absoluta prioridade. ${ }^{26}$

Nessa linha, a absoluta prioridade conferida aos idosos diz que o próprio envelhecer se trata de um direito personalíssimo e sua proteção é um direito social, a ser concretizado precipuamente pela família. ${ }^{27}$

O envelhecer é, pois, direito de personalidade ${ }^{28}$, que incide "sobre a vida da pessoa, a saúde física, a sua integridade física, a sua honra, a sua liberdade física e psicológica, o seu nome, a sua imagem, a reserva sobre a intimidade da sua vida privada". ${ }^{29}$

te originário, a fim de verificar se este teria, ou não, violado os princípios de direito suprapositivo que ele próprio havia incluído no texto da mesma Constituição. - Por outro lado, as cláusulas pétreas não podem ser invocadas para sustentação da tese da inconstitucionalidade de normas constitucionais inferiores em face de normas constitucionais superiores, porquanto a Constituição as prevê apenas como limites ao Poder Constituinte derivado ao rever ou ao emendar a Constituição elaborada pelo Poder Constituinte originário, e não como abarcando normas cuja observância se impôs ao próprio Poder Constituinte originário com relação as outras que não sejam consideradas como cláusulas pétreas, e, portanto, possam ser emendadas. Ação não conhecida por impossibilidade jurídica do pedido. (Supremo Tribunal Federal. Tribunal Pleno. ADI 815. Relator: Ministro Moreira Alves. Julgado em: 28 mar. 1996. DJ 10 maio 1996. p-15131 ement v.-01827-02 pp-00312).

25 Art. 1.641, II, Código Civil de 2002.

26 Art. $3^{\circ}$, Estatuto do Idoso.

27 Arts. $8^{\circ}$ e $3^{\circ}$, V, do Estatuto do Idoso.

28 PINTO, Carlos Alberto da Mota. Teoria geral do direito civil. Coimbra: Coimbra, 2005, p. 207-208. "Designa-se por esta fórmula um certo número de poderes jurídicos pertencentes a todas as pessoas, por força do seu nascimento - verdadeiros Direitos do Homem no sentido das Declarações universais sobre a matéria [...] direitos integradores de relações entre particulares”.

29 Idem, p. 209. 
Trata-se, pois, de um "círculo de direitos necessários”30, ou seja ‘um conteúdo mínimo e imprescindível da esfera jurídica de cada pessoa, de caráter irrenunciável e intransmissível.

$\mathrm{O}$ asseguramento desse direito é, sem dúvida, o fim do Estatuto, que elegeu precipuamente a família ${ }^{31}$ para priorizá-la por meio da efetivação do direito à vida, à saúde, à alimentação, à educação, à cultura, ao esporte, ao lazer, ao trabalho, à cidadania, à liberdade e ao respeito à convivência familiar e comunitária. ${ }^{32}$

Isso porque a proteção e efetivação desse feixe mínimo de direitos dizem que o mais natural e humano dos direitos ${ }^{33}$ é o direito à família, porque é nela que tudo principia ${ }^{34}$, especialmente pelas relações agora marcadas pelo afeto e pela solidariedade, que apontam a verificação dos fenômenos da repersonalização ${ }^{35}$ e da constitucionalização ${ }^{36}$ do direito de família brasileiro.

Dada a importância da família para o Estado, o Estatuto do Idoso prioriza a manutenção dos vínculos familiares, de sorte que o idoso tenha direito de ser mantido em sua família, ao tempo em que esta tem o dever de assisti-lo na velhice, fazendo um pouco do passado e um pouco do presente se intercalarem "dentro

30 Idem, p. 209.

31 Art. $3^{\circ}$, V, Lei n. 10.741/2003.

32 Art. $3^{\circ}$, caput, Lei n. 10.741/2003.

33 BARROS, Sérgio Resende de. Direitos humanos da família. In: DEL’OMO, Florisbal de Souza; ARAÚJO, Luiz Ivani de Amorim (Coord.). Direito de família contemporâneo e os novos direitos: estudos em homenagem ao professor José Russo. Rio de Janeiro: Forense, 2006. p. 137-143.

34 PEREIRA. Rodrigo da Cunha. Família: direitos humanos, psicanálise e inclusão social. In: DEL’OMO, Florisbal de Souza; ARAÚJO, Luiz Ivani de Amorim (Coord.). Direito de família contemporâneo e os novos direitos: estudos em homenagem ao professor José Russo. Rio de Janeiro: Forense, 2006, p. 115-122.

35 LÔBO, Paulo Luiz Neto. A repersonalização das relações de família. In: DEL’OMO, Florisbal de Souza; ARAÚJO, Luiz Ivani de Amorim (Coord.). Direito de família contemporâneo e os novos direitos: estudos em homenagem ao professor José Russo. Rio de Janeiro: Forense, 2006, p. 99-114. Ensina o autor que "a excessiva preocupação com os interesses patrimoniais que matizaram o direito de família tradicional não encontra eco na família atual, vincada por outros interesses de cunho pessoal ou humano, tipificados por um elemento aglutinado e nuclear distinto: a afetividade. Esse elemento nuclear define o suporte fático da família tutelada pela Constituição, conduzindo ao fenômeno que denominamos repersonalização".

36 Ibid., p. 99-114. Acerca da constitucionalização do direito de família, refere o autor a expansão da proteção do Estado conferida à família na Carta Constitucional brasileira de 1988, entre outros aspectos. 
de um contexto maior das relações familiares, na solidariedade que deve existir entre seus membros". ${ }^{37}$ Nessa linha, como ensina Jean Carbonier ${ }^{38}$, a família

no es uma entidad distinta de SUS miembros, sino em cada uno de sus miembros, la parte de la personalidad que está familiarizada, de la misma manera que la conciencia colectiva, según Durkheim (por lo menos, si seguirmos la concepción más razonable), nos es um espíritu transcendente que flota por encima de la sociedade, sino, en el animal sociable, la porción de la conciencia que está socializada.

Esse entendimento, todavia, exige $o$ reconhecimento ${ }^{39}$ desse grupo de pessoas denominado idosos, que reclama o respeito devido, que "não é um acto de gentileza para com os outros. É uma necessidade humana vital”. ${ }^{40}$ É, pois, a necessidade de reconhecimento daqueles que não raro figuram como os "outros-importantes”"41 na formação da mente humana.
Isso porque a definição da nossa identidade passa pelo "diálogo sobre, e, por vezes, contra, as coisas que os nossos outros-importantes querem ver assumidas em nós. Mesmo depois de deixarmos para trás alguns desses outros-importantes - os nossos pais, por exemplo - e se eles desaparecerem de nossas vidas, o diálogo com eles continua para o resto de nossas vidas." ${ }^{42}$

E esse diálogo é possível por meio do asseguramento do convívio familiar entre netos e avós, o que será objeto de análise das próximas linhas.

\section{O DIREITO AO CONVÍVIO FAMILIAR ENTRE AVÓS E NETOS}

A proteção conferida à família tem como fundamento a tutela da própria pessoa humana. Como bem diz Cristiano Chaves de Farias, "não há mais proteção à família pela família, senão em razão do ser humano"³,

37 PEREIRA, Tânia da Silva. Direito da criança e do adolescente: uma proposta interdisciplinar. 2. ed. Rio de Janeiro: Renovar, 2008, p. 285.

38 CARBONNIER, Jean. Derecho flexible: para una sociologia no rigorosa del derecho. Madrid: Tecnos, 1974, p. 188.

39 TAYLOR, Charles. Multiculturalismo. [s.l.]: Instituto Piaget. 1994, p. 45.

40 Idem, p. 46.

41 Idem, p. 53.

42 Ibidem.

43 FARIAS, Cristiano Chaves de. Escritos de direito de família. Rio de Janeiro: Lúmen Júris, 2007, p. 10. 
apontando "evolução da ideia de família-instituição, com proteção justificada por si mesmo, importando não raro violação dos interesses das pessoas nelas compreendidas (especialmente os infantes), para o conceito de família--instrumento do desenvolvimento da pessoa humana". ${ }^{44}$

$\mathrm{Na}$ linha do desenvolvimento da pessoa humana e da proteção de sua dignidade exsurge o princípio do melhor interesse da criança e do adolescente cujas raízes sustentamse "na mudança havida na estrutura familiar nos últimos tempos, através da qual ele despojou-se da sua função econômica para ser um núcleo de companheirismo e afetividade." ${ }^{45}$

Nessa ordem de ideias, o asseguramento do convívio entre avós e netos, a par de ser um direito natural, trata-se da efetivação e da preservação dos direitos de personalidade de ambos. E o direito dos netos em conhecer sua própria história, por meio de seus progenitores, diz respeito ao conhecimento da identidade daqueles, bem como da formação de sua personalidade, qual seja, o exercício do direito de visitas entre netos e avós.
O art. 227, caput, da Constituição Federal de 1988 elenca como direito fundamental de crianças e adolescentes o direito à convivência familiar a ser assegurado prioritariamente pela família. Aí encontrando seu fundamento de validade, o Estatuto da Criança e do Adolescente estabelece, em seu art. 19, que "toda a criança ou adolescente tem o direito de ser criado e educado no seio de sua família [...] assegurada a convivência familiar”. A convivência familiar é também assegurada ao Idoso no artigo $3^{\circ}$ do Estatuto que lhe protege.

A par disso, tanto o Estatuto do Idoso quanto o Estatuto da Criança e do Adolescente conferiram, igual e respectivamente, absoluta prioridade ao idoso e à criança e ao adolescente ${ }^{46}$, de sorte que a leitura dessas fontes legislativas, de forma convergente, faz-se necessária, para que se lhes garanta o direito à convivência entre si, pois tal diz respeito à proteção da própria sociedade. ${ }^{47}$

Seguindo essa tendência, sobreveio a Lei n. 12.398 de 28 de março de 2011, conferindo o direito de visita dos avós aos netos, alterando o Códi-

44 Idem, p. 11.

45 PEREIRA, Rodrigo da Cunha. Princípios fundamentais norteadores para o direito de família. Belo Horizonte: Del Rey, 2006, p. 126.

46 Art. $3^{\circ}$, caput, Lei n. 10.741/2003.

47 Nesse sentido, BOSCHI, Fábio Bauab. Direito de visita. São Paulo: Saraiva, 2005, p. 74. 
go Civil e o Código de Processo Civil. Isso porque a visita dos avós aos netos é vista como modo de preservar o vínculo afetivo, bem como assegurar o desenvolvimento destes no seio de sua família. Tânia da Silva Pereira anota que "reconheceu-se, também, que deste convívio depende, muitas vezes, a formação da criança, pois é inegável que a experiência de vida adquirida poderá ser passada ajudando nesta proposta, sem esquecermos os benefícios do fortalecimento dos vínculos e da relação afetiva entre estes". ${ }^{48}$

No atual panorama social, em que a genitora ausenta-se do lar para inserir-se no mercado de trabalho, contribuindo financeiramente para a manutenção do lar, a figura dos avós, com o seu auxílio e ímpar dedicação à prole de seus filhos, pode ser apontada como uma das características da vida moderna. Isso sem considerar que "o idoso é imprescindível na vida de uma criança. Caso contrário elas seriam membros de uma sociedade sem passado, sem memória e sem compromisso, uma sociedade de pura competição que pode facilmente autodestruir-se". 49
Sob a ótica do direito de personalidade do visitado, Fábio Bauab Boschi $^{50}$ anota que "analisando-se o direito de visita, tomando-se como referencial a pessoa do visitado, sua natureza jurídica assume uma faceta diferenciada. O visitado, por ser aquele que detém um interesse superior, ao que subordinam os demais, é o verdadeiro titular do direito de visita”.

$\mathrm{Na}$ linha da reciprocidade do direito de visita avós-netos, pontua Álvaro Villaça Azevedo ${ }^{51}$ que, nesse intercâmbio familiar, "os netos têm o direito e o dever de cuidar de seus avós, de procurá-los, de assisti-los, em todos os momentos, bons e difíceis”.

No direito francês, a especificidade do tema também mereceu destaque e já foi positivada. O art. 371-4 do Code Civil, com a redação que lhe foi dada pela Lei n. 2002-305 de 04 de março de 2002, estabelece que:

L'enfant a le droit d'entretenir des
relations personnelles avec ses
ascendants. Seuls des motifs graves
peuvent faire obstacle à ce droit. Se
tel est l'intérêt de l'enfant, le juge aux
affaires familiales fixe les modalités
des relations entre l'enfant et un tiers,
parent ou non.

48 PEREIRA, Tânia da Silva. Ob. cit., p. 285.

49 PEREIRA, Tânia da Silva. Ob. cit., p. 284. Nesse ponto, a autora faz referência aos ensinamentos de Odson Costa Ferreira.

50 BOSCHI, Fábio Bauab. Ob. cit., p. 76.

51 AZEVEDO, Álvaro Villaça. Direitos e deveres dos avós: alimentos e visitação. $R e-$ vista IOB de Direito de Família, Porto Alegre, dez. 2008, p. 38-65. 
Dito dispositivo legal foi, novamente, modificado pela Lei n. 2007293 de 05 de março de 2007, que reafirmou a proteção da infância, ao modificar as condições em que aos avós poderiam se recusar o direito de visita de seus netos. $\mathrm{O}$ artigo 3714, alínea 1 , prevê doravante que "a criança tem o direito de manter uma relação pessoal com seus ascendentes. Apenas o interesse da criança poderia constituir obstáculo ao exercício desse direito". A alínea 2 do mesmo texto dá competência ao juiz de família para fixar "as modalidades de relação entre a criança e um terceiro, parente ou não". Nessa linha, o artigo 3714, alínea 1, do Código Civil francês funda as relações pessoais da criança com seus avôs, tendo como pressuposto a proteção do melhor interesse da criança em manter tais relações. ${ }^{52}$

No direito português, a reciprocidade do direito de visita em pauta tornou-se regra, pois a "lei n. 84/95 aditou ao C.C. $o$ art. $1887^{\circ}$-A, que consagra um verdadeiro direito de visita aos avós, cujo reconhecimento já não está condicionado aos pressupostos do art. $1.918^{\circ 53}$, estabelecendo a novel redação que 'os pais não podem injustificadamente privar os filhos do convívio com os irmãos e ascendentes". A matéria, considerando o novel regramento, já foi alvo de exame do Supremo Tribunal de Justiça português, no julgamento do agravo 4217/97:

Este normativo acabou por introduzir, no fim de contas, de modo expresso, um limite ao exercício do poder paternal (cfr. artigo 36 ns. 5 e 6 da Constituição da República e artigos 1885 a 1887 do Código Civil), proibindo os pais de impedir, sem justificação plausível, o normal relacionamento dos filhos com os avós - hipótese que aqui importa ter em conta. Reconhecendo que as relações com os avós são da maior importância para os ne-

52 GOUTTENOIRE, Adeline. Le droit de l'enfant d'entretenir des relations personnelles avec ses grands-parents. Actualité Juridique Famille, n. 4, p. 133-176, avr. 2008. Tradução livre da autora :[...] Parece, entretanto, que esta reescritura não modifica o espírito do texto, que visa proteger as relações da criança com seus ascendentes que não seu pai e mãe. O princípio fixa que essas relações são conformes ao interesse da criança e que ela pertence ao pai e à mãe, os quais, pretendendo o contrário, arcam com a prova. A modificação do texto objetiva evitar o agravamento do conflito pela demonstração dos motivos graves. De outro lado, a nova redação da alínea 1 do artigo 371-4 convida as jurisdições de base a fazerem sua apreciação sobre a oportunidade, para a criança numa relação com seus ascendentes, e não sobre o conflito que opõe estes a seus pais.

53 DELANHESE, Daniele Gervazoni. Uma visão intimista do direito de visita dos avós construída sob os pilares da família moderna e do novo relacionamento entre pais e filhos. In: CAMPOS, Diogo Leite de (Coord.). Estudos sobre o direito das pessoas. Coimbra: Almedina, 2007, p. 71-86. 
tos, ao menos em princípio, quer pela afetividade que recebem, quer pelo desenvolvimento do espírito familiar que proporcionam, o legislador consagrou "um direito de o menor se relacionar” com os avós, que poderá ser designado por “direito de visita”. Com este "direito de visita", genericamente entendido como o estabelecimento de relações pessoais entre quem está unido por estreitos laços familiares, pretendeu-se tutelar a ligação de amor, de afeto, de carinho e de solidariedade existente entre os membros mais chegados da família. Na verdade, é preciso não esquecer que, em regra, o relacionamento do menor com os avós contribui decisivamente "para a sua formação moral” e da sua personalidade ainda em embrião e "constitui um meio de conhecimento das suas raízes e da história da família, de exprimir afeto e de partilhar emoções, ideias e sentimentos de amizade” (BMJ N475 ANO1998 PAG705).

Assim, é certo que o direito de visita de avós e netos insere-se no direito de proteção à convivência familiar, como meio de preservação da própria sociedade, valendo-se de tutela específica, por meio das disposições constitucionais, que remetem inequivocamente à aplicação da Lei de Proteção ao Idoso.

A matéria alimentar, igualmente, conta com regramento específico no que refere ao idoso, o que será objeto de exame do próximo ponto.

\section{O DIREITO E O DEVER ALIMENTAR DOS IDOSOS}

No que tange aos alimentos, as pessoas idosas podem figurar como credoras ou devedoras, conforme suas necessidades e possibilidades em uma e outra situação. A exemplo do envelhecimento, o direito a alimentos trata-se, para o credor, de um direito da personalidade. Enquanto direito fundamental existencial, recentemente, a alimentação ${ }^{54}$ foi positivada como sendo um direito social, por força da Emenda Constitucional n. 64/2010. ${ }^{55}$

54 Consoante a exposição de motivos n. 02/2009-Consea, a garantia do direito humano à alimentação adequada e saudável está expressa em vários tratados internacionais, reconhecidos pelo governo brasileiro, incluindo a Declaração Universal dos Direitos Humanos, o Pacto Internacional dos Direitos Econômicos, Sociais e Culturais, de 1966, e a Cúpula Mundial de Alimentação, de 1996, onde os chefes de Estado reafirmaram "o direito de toda a pessoa a ter acesso a alimentos seguros e nutritivos, em consonância com o direito à alimentação adequada e com o direito fundamental de toda pessoa de estar livre da fome”.

55 Art. $6^{\circ}$ São direitos sociais a educação, a saúde, a alimentação, o trabalho, a moradia, o lazer, a segurança, a previdência social, a proteção à maternidade e à infância, a assistência aos desamparados, na forma desta Constituição (Redação dada pela Emenda Constitucional $n^{\circ}$ 64, de 2010). 
“Alimentos”, no trânsito jurídico, "são prestações para satisfação das necessidades vitais de quem não pode provê-las por si”. ${ }^{56}$ A expressão, no entanto, "designa medidas diversas, compreendendo tudo aquilo que é estritamente necessário à manutenção da vida de uma pessoa - o necessarium vitae -, como alimentação, a cura, o vestuário e a habitação, ora abrangendo outras necessidades, como as intelectuais e morais - o necessarium personae -, nos quais se leva em conta a qualidade do alimentando e os deveres da pessoa obrigada". ${ }^{57}$ "Os primeiros denominam-se alimentos naturais, os outros civis ou côngruos". ${ }^{58}$

No direito brasileiro, o Código Civil de 2002, reservou à disciplina dos alimentos os artigos 1.694 a 1.710 , dispondo-os no Subtítulo III do Título II do Livro IV do Direito de Família, para esclarecer, desde logo, que os alimentos necessários "para viver de modo compatível à sua condição social, inclusive para atender às necessidades de sua educação” podem ser pedidos aos parentes, ao cônjuge ou companheiros (art. 1.694, caput, $\mathrm{CC}$ ), e "devem ser fixados na proporção das necessidades do reclamante e dos recursos a pessoa obrigada" (art. $\left.1.694, \S 1^{\circ}, \mathrm{CC}\right)$. Versa esse último sobre o binômio possibilidade/necessidade, que funciona como baliza para a fixação do quantum alimentar.

Ao seu turno, o artigo 1.696 estabelece a reciprocidade do direito alimentar entre pais e filhos, a par de determinar expressamente que esse mesmo direito é extensivo a todos os ascendentes, mas acentua, em seu art. 1.698, que "se o parente, que deve alimentos em primeiro lugar, não estiver em condições de suportar totalmente o encargo, serão chamados a concorrer os de grau imediato, sendo várias as pessoas obrigadas a prestar alimentos, todas devem concorrer na proporção dos respectivos recursos, e, intentada ação contra uma delas, poderão as demais ser chamadas para integrar a lide". ${ }^{59}$

Os precitados dispositivos apontam as linhas gerais que pautam o direito e o dever aos alimentos, quais sejam, o dever recíproco entre parentes e cônjuges, incluindo entre os primeiros os ascendentes, e o caráter subsidiário da obrigação, quando os que devem alimentos em primeiro lugar não tiverem condições ou não pu-

56 GOMES, Orlando. Direito de Família. 12. ed. Rio de Janeiro: Forense, 2000, p. 427. 57 CAHALI, Yussef Said. Dos Alimentos. 4. ed. ampl. e atual. de acordo com novo Código Civil. São Paulo: Editora Revista dos Tribunais, 2002, p. 19.

58 GOMES, op. cit., p. 427.

59 Ref. artigos do Código Civil de 2002. 
derem prestá-la, e, por fim, a quantificação dos alimentos, que devem ser fixados na medida das necessidades do alimentando e das possibilidades do alimentante.

Acerca do tema, calha a lição de Yussef Said Cahali: ${ }^{60}$

O grau mais próximo exclui o mais remoto, sendo o primeiro lugar na escala dos obrigados ocupado pelos genitores; apenas se faltam os genitores, ou se estes se encontram impossibilitados financeiramente de fazê-lo, estende-se a obrigação de alimentos aos ulteriores ascendentes, respeitada a ordem de proximidade.

O Estatuto do Idoso, ao seu turno, estabelece que "os alimentos serão prestados aos idosos na forma da lei civil" ${ }^{61}$, mas logo esclarece que “a obrigação alimentar é solidária, podendo o idoso optar entre os prestadores". ${ }^{62}$ Assim, "se o idoso e seus familiares não possuírem condições econômicas de prover o seu sustento, impõe-se ao Poder Público esse provimento, no âmbito da assistência social”. ${ }^{64}$
Em recente julgado, decidiu a Oitava Câmara Cível do Tribunal de Justiça do Estado do Rio Grande do Sul que ao idoso, na condição de credor alimentar, faculta-se liberdade para demandar contra quem bem entender, não se afigurando razoável obrigá-lo a litigar contra todos os filhos, solidariamente. O acórdão foi assim ementado:

APELAÇÃO. AÇÃO DE ALIMENTOS. ESTATUTO DO IDOSO. CHAMAMENTO AO PROCESSO DOS DEMAIS FILHOS. DESCABIMENTO. TRINÔMIO ALIMENTAR. ADEQUAÇÃO. Da redação do art. 12 da Lei 10.741/03 (Estatuto do Idoso), denota-se a liberdade deste para demandar contra quem bem entender. Assim, não se afigura razoável obrigá-lo a litigar contra todos os filhos, pois fica a seu critério decidir de quem exigirá a pensão. Ademais, o apelante não conseguiu demonstrar sua impossibilidade de arcar com o pensionamento estipulado. NEGARAM PROVIMENTO. ${ }^{64}$

Essa é também a orientação do Superior Tribunal de Justiça, como se

60 CAHALI, Yussef Said. Dos Alimentos. 4. ed. ampl. e atual. de acordo com novo Código Civil. São Paulo: Editora Revista dos Tribunais, 2002, p. 677.

61 Lei n.10.741/2003, art. 11.

62 Lei n.10.741/2003, art. 12.

63 Lei n.10.741/2003, art. 14.

64 RIO GRANDE DO SUL. Tribunal de Justiça. Oitava Câmara Cível. Apelação Cível No 70026052613. Relator: Rui Portanova. Julgado em: 04 dez. 2008. 
vê no julgamento do REsp 775.565/ SP, que teve como Relatora a Ministra Nancy Andrighi:

Direito civil e processo civil. Ação de alimentos proposta pelos pais idosos em face de um dos filhos. Chamamento da outra filha para integrar a lide. Definição da natureza solidária da obrigação de prestar alimentos à luz do Estatuto do Idoso. - A doutrina é uníssona, sob o prisma do Código Civil, em afirmar que o dever de prestar alimentos recíprocos entre pais e filhos não tem natureza solidária, porque é conjunta.

- A Lei 10.741/2003 atribuiu natureza solidária à obrigação de prestar alimentos quando os credores forem idosos, que por força da sua natureza especial prevalece sobre as disposições específicas do Código Civil.

- O Estatuto do Idoso, cumprindo política pública (art. $3^{\circ}$ ), assegura celeridade no processo, impedindo intervenção de outros eventuais devedores de alimentos.

- A solidariedade da obrigação alimentar devida ao idoso lhe garante a opção entre os prestadores (art. 12). Recurso especial não conhecido (DJ 26/06/2006 p. 143).

Em contrapartida, poderá o idoso figurar em determinada relação jurídica como devedor de alimentos, podendo a obrigação ser subsidiária ou não, conforme o caso. Será o longevo devedor em primeiro lugar quando responsável pelo sustento de seus filhos, do cônjuge ou do companheiro ${ }^{65}$, mas subsidiariedade haverá quando se tratar de alimentos ao netos, quando os primeiros obrigados forem ausentes ou não puderem prestá-los. ${ }^{66}$

Em recente julgado, decidiu a Sétima Câmara Cível do Tribunal de Justiça gaúcho que o dever alimentar dos avós possui caráter subsidiário, de sorte que não demonstrada a ausência ou total impossibilidade dos genitores, descabe atribuir aos avós tal ônus. O acórdão em questão foi assim ementado:

APELAÇÃO CÍVEL. DIREITO DE FAMÍLIA. ALIMENTOS. OBRIGAÇÃO AVOENGA. SOMENTE ADMISSÍVEL NA IMPOSSIBILIDADE ABSOLUTA DOS GENITORES CUMPRIREM A OBRIGAÇÃO. Compete aos genitores a obrigação de sustento dos filhos e na falta de um, ao outro, primordialmente, em decorrência do poder familiar. A obrigação alimentar dos avós, nos termos do art. 1.696 do Código Civil, detém característica subsidiária ou complementar, somente se justificando nos casos em que restar comprovada a incapacidade absoluta dos pais. Não demonstrada a ausência dos pais ou a total impossibilidade econômica deles em prover o sustento do filho, descabe atribuir ao avô paterno tal ônus, mormente quando este é idoso, recebe parcos rendimentos de apo-

65 Art. 1.694, Código Civil de 2002.

66 Art. 1.698, Código Civil de 2002. 
sentadoria e tem gastos elevados com medicamentos, uma vez que padece com sérios problemas de saúde. APELAÇÃO DESPROVIDA. ${ }^{67}$

As situações destacadas decorrem das disposições constitucionais e legais acerca dos alimentos, de sorte que na condição de devedor alimentar eventualmente não poderá o idoso socorrer-se de sua própria lei de proteção, mas se ostentar ele a condição de credor alimentar poderá valer-se do regramento especial (Lei n. 10.741/2003) e optar entre os prestadores.

No papel de devedor de alimentos, o idoso poderá ainda ser condenado a prover os denominados alimentos gravídicos, objeto de análise do próximo ponto.

\section{OS ALIMENTOS GRAVÍDICOS E A OBRIGAÇÃO AVOENGA}

Com o advento da Lei $n$. $11.804 / 2008$, que instituiu os deno- minados alimentos gravídicos, renovam-se os questionamentos acerca da obrigação avoenga relativamente ao “devedor” indicado na nova lei.

A Lei em questão disciplina, em apenas seis artigos, o direito de alimentos da mulher gestante e a forma como será exercido ${ }^{68}$, para estabelecer que ditos alimentos compreendem "os valores suficientes para cobrir as despesas adicionais do período da gravidez e que sejam dela decorrentes, da concepção ao parto, inclusive as referentes a alimentação especial, assistência médica e psicológica, exames complementares, internações, parto, medicamentos e demais prescrições preventivas e terapêuticas indispensáveis, a juízo do médico, além de outras que o juiz considere pertinentes". ${ }^{9}$

A par da abrangência alimentar prevista na lei em exame, esta prevê que os alimentos referem-se à "parte das despesas que será custeada pelo futuro pai" ${ }^{70}$, na medida de suas possibilidades, e serão fixados pelo juiz mediante a existência de indícios da paternidade. ${ }^{71}$ "Após o nascimento

65 Art. 1.694, Código Civil de 2002.

66 Art. 1.698, Código Civil de 2002.

67 RIO GRANDE DO SUL. Tribunal de Justiça. Sétima Câmara Cível. Apelação Cível No 70026725374. Relator: André Luiz Planella Villarinho. Julgado em: 12 ago. 2009.

68 Art. $1^{\circ}$ da Lei n. $11.804 / 2008$.

69 Art. $2^{\circ}$ da Lei n. 11.804/2008.

70 Art. $2^{\circ}$, parágrafo único, da Lei n. 11.804/2008.

71 Art. $6^{\circ}$ da Lei n. 11.804/2008. 
com vida, os alimentos gravídicos ficam convertidos em pensão alimentícia em favor do menor até que uma das partes solicite sua revisão". ${ }^{72}$

A Lei 11.804/2006 refere expressamente a disciplina do "direito de alimentos da mulher gestante" 73 , mas seguramente busca a proteção dos direitos do nascituro, pois, ainda que destituído de personalidade civil, já que esta "resulta da entrada do ser humano no mundo jurídico"74, a lei brasileira põe a salvo os seus direitos desde a concepção. ${ }^{75}$ Trata-se a gestante de mero instrumento à proteção do nascituro, pois visa os alimentos "suficientes para cobrir as despesas adicionais do período da gravidez" ${ }^{76}$

Aurélio Buarque de Holanda ${ }^{77}$ ensina que nascituro é aquele "que há de nascer”, a par de anotar que embrião é “o ser humano nas primeiras fases de desenvolvimento, i.e., do fim da segunda até o final da oitava semana, quando termina a morfogênese geral”. ${ }^{78}$ A gravidez, assim, "começa com a nidação (isto é, quando o ovo de implanta no endométrio, revestimento interno do útero)" ${ }^{79}$

No direito francês, "o nascituro tem personalidade condicional, porque ela depende do nascimento com vida e da viabilidade" 80 , sendo que "a afirmação de não se poder ser, ao mesmo tempo, sujeito e objeto - conforme o faz o Comitê Nacional de Ética da França - induz o reconhecimento de ser o nascituro sujeito de direitos. O art. 314 do Código Civil confirma esta tese, admitindo que a qualidade de filho legítimo remonta à concepção". ${ }^{81}$

Para o direito italiano, ao nascituro são resguardados alguns direitos patrimoniais, como o de receber doa-

72 Art. $6^{\circ}$, parágrafo único, da Lei n. 11.804/2008.

73 Art. $1^{\circ}$ da Lei n. 11.804/2008.

74 PONTES DE MIRANDA, Francisco Cavalcanti. Tratado de direito privado. Rio de Janeiro: Borsoi, 1956. v. 7, p. 6.

75 Art. $2^{\circ}$ do Código Civil de 2002.

76 Art. $2^{\circ}$ da Lei n. 11.804/2008.

77 NASCITURO. In: FERREIRA, Aurélio Buarque de Holanda. Novo Aurélio Século XXI: o dicionário da língua portuguesa. 3. ed. Rio de Janeiro, 1999, p. 1393.

78 Ibid., p. 735.

79 MARANHÃO apud ALMEIDA, Silmara J. A. Chinelato. Tutela civil do nascituro. São Paulo: Saraiva, 2000, p. 11.

80 Ibid., p. 61.

81 Ibid., p. 63. 
ção (art. 462), bem como se admite substituição fideicomissária a favor do nascituro não concebido (art. 692. primeiro e segundo parágrafos), entre outros. No entanto, "diante da insuficiência da proteção pelo Código Civil e da dicção estatalista do art. $1^{\circ}$, a vida do nascituro encontra abrigo na Constituição Federal e nas convenções internacionais". ${ }^{82}$

Discorrendo sobre os direitos de personalidade, ensina Pontes de Miranda $^{83}$ que "entre os direitos que se resguardam ao nascituro estão os direitos à integridade, física e psíquica, e à vida, pelos quais hão de zelar os pais ou o curador ao ventre (arts. $4^{\mathrm{o}}, 2^{\mathrm{a}}$ parte, 458 e 462, e os outros direitos de personalidade)".

Nessa ordem de ideias, é correto afirmar que a lei que instituiu os alimentos gravídicos está em conformidade com a teoria natalista ${ }^{84}$, adotada pelo Código Civil de 2002 (art. $2^{\circ}$ ), segundo a qual a personalidade começa do nascimento com vida, resguardando-se os direitos do nascituro. A lei em comento, pois, não deixou margens para entendimento diverso, pois se referiu expressamente à gravidez, que se trata de condição necessária e suficiente para a incidência da norma.

A gestante encontra-se, com efeito, legitimada a proteger o ser que está em seu ventre, bastando que comprove em juízo a "existência de indícios da paternidade" 85 , o que não é novidade no ordenamento jurídico pátrio, pois em nome da proteção aos direitos do nascituro, antes do advento da Lei que instituiu os alimentos gravídicos, já havia decidido o Tribunal de Justiça do Estado do Rio Grande do Sul:

UNIÃO ESTÁVEL. ALIMENTOS
PROVISÓRIOS. EX-COMPANHEI-
RA E NASCITURO. PROVA. 1.
Evidenciada a união estável, a pos-
sibilidade econômica do alimentante
e a necessidade da ex-companheira,
que se encontra desempregada e
grávida, é cabível a fixação de ali-
mentos provisórios em favor dela
e do nascituro, presumindo-se seja

82 Ibid., p. 72.

83 PONTES DE MIRANDA, 1956, p. 10.

84 Silmara Almeida anota que, no direito brasileiro, há três correntes fundamentais acerca do início da personalidade: a natalista, a da personalidade condicional e a concepcionista. Diz a autora: "a primeira sustenta que a personalidade começa do nascimento com vida. A segunda afirma que a personalidade começa com a concepção, com a condição do nascimento com vida (doutrina da personalidade condicional ou concepcionista imprópria). A terceira considera que o início da personalidade se inicia com a concepção" (ALMEIDA, 2000, p. 145).

85 Art. $6^{\circ}$ da Lei n. 11.804/2008. 
este filho das partes. 2. Os alimentos poderão ser revistos a qualquer tempo, durante o tramitar da ação, seja para reduzir ou majorar, seja até para exonerar o alimentante, bastando que novos elementos de convicção venham aos autos. Recurso provido em parte. (SEGREDO DE JUSTIÇA.) $)^{86}$

Havendo indícios da paternidade, estes devem orientar a verificação dos parentes do nascituro, de sorte que os progenitores poderão igualmente ser chamados a prestar alimentos ao infante concebido de forma subsidiária e complementar, em conformidade com o disposto no art. 1.698 do Código Civil, que "repete a ordem sucessiva dos graus de parentesco na obrigação alimentar, de modo que dentro dessa ordem podem ser demandados vários parentes numa mesma ação, na medida de suas possibilidades”. ${ }^{87}$

\section{CONSIDERAÇÕES FINAIS}

O Estatuto do Idoso busca garantir efetiva proteção a esse grupo de pessoas identificado objetivamente pelo legislador como vulnerável, com base essencialmente em um critério etário, que traduz a velhice como uma categoria social construída. Essa mesma lei especial determina expressamente à família, à sociedade e ao Estado priorizar o atendimento à pessoa idosa. A absoluta prioridade, a proteção do melhor interesse e a proteção integral são as diretrizes desse regramento, pautado que é pelo dever geral de solidariedade, positivado na Constituição Federal de 1988, como um de seus objetivos, como forma de proteção da dignidade da pessoa humana, um de seus fundamentos.

$\mathrm{O}$ aumento significativo do número de idosos trata-se de um fenômeno atual que vem se acentuando cada vez mais. A sociedade pós-moderna ${ }^{88}$ guardaria lógica e coerência se compreendesse a velhice como um verdadeiro troféu - visível nas rugas e nos cabelos brancos -, conferido àqueles que alcançaram a longevidade.

A família da pós-modernidade tem como elemento de visibilidade o afeto, ao tempo em que mantém sua coesão em razão do desenvolvimento

86 RIO GRANDE DO SUL. Tribunal de Justiça. Sétima Câmara Cível. Agravo de Instrumento N ${ }^{0}$ 70017520479, Relator: Sérgio Fernando de Vasconcellos Chaves. Julgado em: 28 mar. 2007.

87 SILVA, 2006, p. 1.395.

88 Antonio Junqueira Azevedo pontua algumas características dos tempos pós-modernos: “a hiper-complexidade, que, no mundo jurídico, se revela na multipliciplidade de fontes do direito, quer materiais - porque hoje são vários os grupos sociais, justapostos 
da personalidade de seus membros e não mais em razão de si mesma. A afetividade desenvolvida no seio da família é pressuposto da realização da pessoa humana e depende do convívio familiar, que deve ser assegurado aos avós e netos, como direito recíproco, tendo em conta o feixe de direitos que envolve essas relações.

Envelhecer é direito de personalidade e, embora a vulnerabilidade da pessoa idosa reconhecida no ordenamento jurídico brasileiro, a especial proteção que lhe é conferida pelo Estatuto do Idoso poderá ser mitiga- da em determinadas situações, como, por exemplo, quando for obrigado a prestar alimentos especialmente aos filhos e netos - e quiçá aos ainda não nascidos, mas já concebidos, caso do nascituro.

O Estado, no exercício de uma de suas funções, qual seja, a legislativa, e com vistas a dar efetividade ao mandamento constitucional da solidariedade, ampliou o espectro de proteção jurídica da pessoa humana também nessa derradeira fase da existência, que igualmente traz consigo relevantes papéis na família e na sociedade.

\section{REFERÊNCIAS}

ALEXY, Robert. Sistema jurídico, principios jurídicos y razon prática. In: JORNADAS INTERNACIONALIES DE LÓGICA E INFORMÁTICA JURÍDICAS, 4., San Sebastián, 1988.

ALMEIDA, Silmara J. A. Chinelato. Tutela civil do nascituro. São Paulo: Saraiva, 2000.

ALVES, José Carlos Moreira. Direito romano. Rio de Janeiro: Forense, 1992. v. 1.

ALVES, Leonardo Barreto Moreira. A Função Social da Família. O Reconhecimento Legal do Conceito Moderno de Família: O art. 5, II, Parágrafo Único, da Lei n. 11.340/2006 (Lei Maria da Penha). Revista Brasileira de Direito de Família, n. 39, p. 131-153, dez./jan. 2007.

AZEVEDO, Álvaro Villaça. Direitos e deveres dos avós: alimentos e visitação. Revista IOB de Direito de Família, Porto Alegre, dez. 2008.

uns aos outros, todos dentro da mesma sociedade, mas valores compartilhados (shared values), e cada um, querendo uma norma ou lei especial para si -, quer formais - com um sem-número de leis, decretos, resoluções, códigos deontológicos, avisos, etc. etc.” (AZEVEDO, Antonio Junqueira de. O Direito pós-moderno e a codificação. Revista de Direito do Consumidor, São Paulo, v. 9, n. 33, p. 123-129, jan.mar. de 2000). 
. O Direito pós-moderno e a codificação. Revista de Direito do Consumidor, São Paulo, v. 9, n. 33, p. 123-129, jan.mar. de 2000. . Estatuto da família de fato. São Paulo: Atlas, 2002.

AZEVEDO, Antonio Junqueira. Caraterização jurídica da dignidade da pessoa humana. Revista dos Tribunais, São Paulo, v. 91, n. 797, p. 11-26, mar. 2002.

- (Coord.). Comentários ao Código Civil: parte especial: do direito das sucessões. São Paulo: Saraiva, 2003. v. 20 (arts. 1.784 a 1.856).

BARROS, Sérgio Resende de. Direitos humanos da família. In: DEL'OMO, Florisbal de Souza; ARAÚJO, Luíz Ivani de Amorim (Coord.) Direito de família contemporâneo e os novos direitos: estudos em homenagem ao professor José Russo. Rio de Janeiro: Forense, 2006, p. 137-143.

BÁRBARA, Ana Teresa dos Santos. O idoso institucionalizado no contexto sociojurídico português. In: CAMPOS, Diogo Leite de (Coord.). Estudos sobre o direito das pessoas. Coimbra: Almedina, 2007. BEAUVOIR, Simone de. A velhice. Tradução de Maria Helena Franco Martins. Rio de Janeiro: Nova Fronteira, 1990.

BOBBIO, Norberto. A era dos direitos. Tradução de Carlos Nelson Coutinho. 11. ed. Rio de Janeiro: Campus, 1992.
O tempo da memória: de senectude e outros escritos autobiográficos. Tradução de Daniela Versiani. Rio de Janeiro: Campus, 1997.

BONFANTE, Pietro. Instittuzioni di diritto romano. 10. ed. Torino: S.P.E di C. Fanton, 1957.

BOSCHI, Fábio Bauab. Direito de visita. São Paulo: Saraiva, 2005. CABREIRA, Carlos Cabral et al. Direitos da criança, do adolescente $e$ do idoso. Belo Horizonte: Del Rey, 2006.

CAHALI, Yussef Said. Dos Alimentos. 4. ed. ampl. e atual. de acordo com novo Código Civil. São Paulo: Editora Revista dos Tribunais, 2002.

CANIATO, Maria Cecília Garreta Prats. Direito civil: parte geral. São Paulo: HARBRA, 2007.

CARBONNIER, Jean. Derecho flexible: para una sociologia no rigorosa del derecho. Madrid: Tecnos, 1974.

CÍCERO, Marco Túlio. Saber envelhecer e a amizade. Tradução de Paulo Neves. Porto Alegre: L\&PM, 2001.

COULANGES, Fustel de. A cidade antiga. Tradução de Fernando de Aguiar. São Paulo: Martins Fontes, 2000.

DEL'OLMO, Florisbal de Souza; ARAÚO, Luís Ivani de Amorim (Coord.). Direito de família contemporâneo e os novos direitos: 
estudos em homenagem ao Professor José Russo. Rio de Janeiro: Forense, 2006.

DELANHESE, Daniele Gervazoni.

Uma visão intimista do direito de visita dos avós construída sob os pilares da família moderna e do novo relacionamento entre pais e filhos. In: CAMPOS, Diogo Leite de (Coord.). Estudos sobre $o$ direito das pessoas. Coimbra: Almedina, 2007, p. 71-86.

FACHIN, Luiz Edson. Direito Além do Novo Código Civil: Novas Situações Sociais, Filiação e Família. Revista Brasileira de Direito de Família. Porto Alegre : Síntese, IBDFAM. Ano V. n. 17.p. 07/35, abr./maio, 2003.

FARIAS, Cristiano Chaves de. Escritos de direito de família. Rio de Janeiro: Lúmen Júris, 2007.

FERREIRA, Aurélio Buarque de Holanda. Novo Aurélio Século XXI: O dicionário da lingual portuguesa. - 3. ed. rev. e ampl. Rio de Janeiro: Nova Fronteira, 1999.

FRANCO, Paulo Alves. Estatuto do Idoso comentado. São Paulo: Editora de Direito, 2004.

GILISSEN, John. Introdução histórica ao direito. 2. ed. Lisboa: Calouste, 1995.

GLANZ, Semy. A família mutante: sociologia e direito comparado, inclusive o novo Código Civil brasileiro. São Paulo: Renovar, 2005. GOMES, Orlando. A caminho dos microssistemas. In: BARROS, Hamilton Moraes e (Org.). Estudos jurídicos em homenagem ao Professor Caio Mário da Silva Pereira. Rio de Janeiro: Forense, 1984.

GOUTTENOIRE, Adeline. Le droit de l'enfant d'entretenir des relations personnelles avec ses grands-parents. Actualité Juridique Famille, n. 4, p. 133-176, avr. 2008.

IRTI, Natalino. Codici di settore: Compimento della 'decodificazione'. Dirito e Societa, n. 2, p. 131-136, 2005.

I cinquant'anni del codice civile. Rivista di Diritto Civile, n. 3, 1992.

KASER, Max. Direito privado romano. Lisboa: Calouste, 1999.

LARENZ, Karl. Derecho Civil. Parte General. 3. ed., 1975. C.H. Beck'sche de Munich. Edersa, 1978.

LEITE, Eduardo de Oliveira. Direito civil aplicado: direito das sucessões. São Paulo: Revista dos Tribunais, 2004.

LÔBO, Paulo Luiz Netto. A constitucionalização do direito civil brasileiro. In: TEPEDINO, Gustavo (Org.). Direito civil contemporâneo: novos problemas à luz da legalidade constitucional. São Paulo: Atlas, 2008. p. 18-28.

A repersonalização das relações de família. In: DEL'OMO, 
Florisbal de Souza; ARAÚJO, Luíz Ivani de Amorim (Coord.) Direito de família contemporâneo e os novos direitos: estudos em homenagem ao professor José Russo. Rio de Janeiro: Forense, 2006, p. 99-114.

MARQUES, Claudia Lima. Constituição, direitos fundamentais e direito privado. In: SARLET, Ingo Wolfgang (Org.). Solidariedade na doença e na morte: sobre a necessidade de "ações afirmativas" em contratos de planos de saúde e de planos funerários frente ao consumidor idoso. 2. ed. rev. e ampl. Porto Alegre: Livraria do Advogado, 2006, p. 187-223.

PONTES DE MIRANDA, Francisco Cavalcanti. Tratado de direito privado. Rio de Janeiro: Borsoi, 1956. v. 7.

NORONHA, Carlos Silveira. Conceito e fundamentos de família e sua evolução na ordem jurídica. Revista Forense, Rio de Janeiro, v. 326, p. 21-31, 1994.
PEREIRA, Caio Mário da Silva. A social da família. Revista Brasileira de Direito de Família, n. 39, p. 155-169, dez./jan. 2007. PEREIRA, Rodrigo da Cunha. (Coord.). Afeto, ética, família e novo código civil. Belo Horizonte: Del Rey, 2004.

PEREIRA, Tânia da Silva. Direito da criança e do adolescente: uma proposta interdisciplinar. 2. ed. Rio de Janeiro: Renovar, 2008.

PINTO, Carlos Alberto da Mota. Teoria geral do direito civil. Coimbra: Coimbra, 2005.

SÉGUIN, Elida. O idoso: aqui e agora. Rio de Janeiro: Lúmen Júris, 2001.

SILVA, Regina Beatriz Tavares da. Novo Código Civil comentado. 5. ed. atual. São Paulo: Saraiva, 2006.

TAYLOR, Charles. Multiculturalismo. [s.l.]: Instituto Piaget. 1994.

TEPEDINO, Gustavo. Temas de direito civil. Rio de Janeiro: Renovar, 2004. 